\title{
ANALISIS PENGARUH PEDAGOGICAL CONTENT KNOWLEDGE TERHADAP TEACHING EFFICACY CALON GURU
}

\author{
Ai Nur Solihat, Universitas Siliwangi \\ ainursolihat@unsil.ac.id \\ Raden Roro Suci Nurdianti, Universitas Siliwangi \\ radenrorosucinurdianti@unsil.ac.id
}

\begin{abstract}
ABSTRAK
Penelitian ini bertujuan untuk mengetahui gambaran mengenai pedagogical content knowledge dan teaching efficacy, serta mengkaji bagaimana pengaruh antara pedagogical content knowledge terhadap teaching efficacy calon guru. Metode yang digunakan yakni survey eksplanatori mencakup populasi mahasiswa tingkat akhir pada FKIP Universitas Siliwangi. Teknik sampling yang digunakan dalam penelitian ini adalah proportionate random sampling. Teknik analisis data yang digunakan dalam penelitian ini adalah statistik deskriptif dan analisis regresi linier sederhana untuk mengetahui pengaruh Pedagogical Content Knowledge terhadap teaching efficacy calon guru. Hasil penelitian menunjukkan bahwa kecenderungan pedagogical content knowledge memiliki pengaruh yang positif pada teaching efficacy.
\end{abstract}

Kata Kunci: Pedagogical Content Knowledge, Teaching Efficacy, Calon Guru.

\section{ABSTRACT}

This study aims to find out about pedagogical content knowledge and teaching efficacy of prospective teachers, and examine how the influence of pedagogical content knowledge on teaching efficacy of prospective teachers. The method used is an explanatory survey covering the final student population at FKIP Siliwangi University. The sampling technique used in this study is proportionate random sampling. Data analysis techniques used in this study are descriptive statistics and simple linear regression analysis to determine the effect of Pedagogical Content Knowledge on the teaching efficacy of prospective teachers. The results showed that the tendency of pedagogical content knowledge has a positive effect on teaching efficacy.

Keywords: Pedagogical Content Knowledge, Teaching Efficacy, Prospective Teachers.

\section{PENDAHULUAN}

Teaching efficacy merupakan variabel fundamental yang memiliki keterkaitan dengan pengetahuan, sikap, maupun keterampilan guru ketika mempraktekkan kegiatan belajar mengajar yang efektif serta efisien. Teaching 
efficacy berkaitan dengan tingkat kepercayaan mahasiswa calon guru dalam melaksanakan tugas mengajar (Depaepe \& König, 2018). Menduduki posisinya sebagai efikasi akademik, konsep tersebut sangat diperlukan oleh mahasiswa calon guru, maupun guru (Redmon, 2007). Semakin rendah efikasi yang dimiliki oleh guru, maka kegiatan-kegiatan yang berkaitan dengan kapabilitasnya tersebut tidak terencana dengan baik. Kemudian, dalam menangani siswa yang bermasalah, guru cenderung tidak gigih, dan juga guru tidak mengajarkan kembali materi dalam pembelajaran melalui cara yang memudahkan siswa (d'Alessio, 2018). Ashton \& Webb (Schunk, 2012) mengemukakan bahwa guru yang efikasi dirinya tinggi relative menciptakan lingkungan kelas yang positif, memfasilitasi ide siswanya, serta memerhatikan kebutuhan para siswanya.

Berdasarkan pengamatan peneliti terkait model pembelajaran, saat ini model yang digunakan dalam pembelajaran cenderung ke arah pengembangan secara kognitif, tapi tidak terlalu mengarah kepada aspek sikap dari calon guru. Dampaknya adalah mahasiswa praktikan yang kurang percaya diri serta efikasi mengajarnya rendah. Selain itu, pembelajaran berlangsung canggung dan tidak yakin dengan penyampaian materi yang dilakukan. Padahal program pembelajaran calon guru sebaiknya dapat meningkatkan teaching efficacy calon guru (d'Alessio, 2018). (Redmon, 2007) mengemukakan bahwa efikasi mengajar merupakan bagian dari program pembelajaran serta praktek pengalaman lapangan sebagai upaya mempersiapkan pembelajaran bagi calon guru.

Usaha yang dilakukan untuk meningkatkan teaching efficacy calon guru salah satunya dengan cara menjalankan praktek pengalaman lapangan. Praktek pengalaman lapangan ini dimaksudkan agar para calon guru mempelajari bagaimana proses pembelajaran itu harus dilakukan. Program pembelajaran merupakan inti dari proses pendidikan itu sendiri, dimana guru merupakan fasilitator utama didalamnya. Guru professional tidak hanya ditunjukkan atau dibuktikan dengan sertifikat profesional melainkan harus ditunjukkan oleh kinerja sebagai seorang pendidik. Oleh karena itu, hampir semua negara di seluruh dunia menentukan tujuan pendidikannya untuk mengembangkan kompetensi professional calon guru (Depaepe \& König, 2018). Guru bukan hanya menguasai materi serta strategi pengajaran, tapi juga harus memiliki pemahaman dan kemampuan khusus dalam mengkombinasikan pengetahuan materi, kurikulum, belajar, pengajaran, dan siswa. Pengetahuan tersebut dapat dikategorikan pada pengetahuan konten pedagogi (pedagogical content knowledge). PCK merupakan gabungan antara pemahaman materi ajar (content knowledge) serta pemahaman cara mendidik (pedagogical knowledge) menjadi sebuah kesatuan yang harus dikuasai guru. Shuell dan Shulman (Eggen \& Kauchak, 2012) menyebutkan bahwa PCK yakni pemahaman berkenaan dengan metode pembelajaran efektif untuk menjelaskan materi tertentu, kemudian pemahaman mengenai apa yang menyebabkan materi tertentu mudah atau sukar untuk dipelajari.

Dua himpunan besar yang membentuk PCK adalah content knowledge serta pedagogical knowledge. Content knowledge berkenaan dengan pengetahuan konsep, teori, ide, kerangka berpikir, serta pembuktian metode pembelajaran. Shulman juga mengemukakan, pedagogical knowledge 
berkenaan dengan cara serta proses pembelajaran yang didalamnya meliputi pengetahuan mengenai manajemen kelas, tugas, dan perencanaan pembelajaran serta pembelajaran siswa (Depaepe \& König, 2018). Sedangkan, kompetensi pedagogik guru merupakan kemampuan dalam pengelolaan pembelajaran peserta didik yang mencakup pemahaman tentang wawasan atau landasan kependidikan, peserta didik, pengembangan kurikulum, perencanaan pembelajaran, pelaksanaan pembelajaran yang mendidik dan dialogis, pemanfaatan teknologi pembelajaran, evaluasi hasil belajar, serta pengembangan peserta didik guna meningkatkan potensi yang dimilikinya.

Penelitian ini bertujuan untuk mengetahui pengaruh pedagogical content knowledge (PCK) terhadap teaching efficacy calon guru. Terdapat banyak penelitian mengenai penerapan Pedagogical Content Knowledge yang menemukan bahwa dampak positif dari PCK berimplikasi pada proses pembelajaran, bagaimana cara guru dalam mengajar atau cara guru dalam menyampaikan materi pembelajaran. Guru yang pedagogical content knowledge (PCK) akan memiliki tingkat kepercayaan diri yang tinggi dalam mengajar sesuai dengan pernyataan (Richardson, Byrne, \& Liang, 2017) bahwa teachers who have higher levels of science teaching efficacy and strong PCK would more likely enact appropriate PCK in classroom teaching. Guru tersebut akan merasa yakin dengan kompetensi yang dimilikinya. Pernyataan tersebut didukung oleh hasil penelitian (Hoy \& Spero, 2005) bahwa teachers with a strong sense of efficacy tend to exhibit greater levels of planning, organization, and enthusiasm and spend more time teaching in subject areas where their sense of efficacy is, whereas teachers tend to avoid subjects when efficacy is lower. Oleh karena itu, teaching efficacy ini penting dikaji lebih mendalam agar dapat menciptakan keyakinan pada seorang guru dalam melaksanakan proses pembelajaran secara efektif.

\section{METODE PENELITIAN}

Metode dalam penelitian ini adalah survey dengan desain eksplanatori. Desain eksplanatori memfokuskan pada eksplanasi hubungan antar-variabel yang diteliti baik hubungan korelasional maupun hubungan kausal, memprediksi perubahan yang terjadi serta mengeksplanasi perbedaan antara dua kelompok (Creswell, 2011). Pengumpulan data dilakukan dengan cara menyebarkan kuesioner teaching efficacy yang diadopsi dari Science Teaching Efficacy Instrument dan kuesioner pedagogical content knowledge (PCK). Melalui Teknik proportionate random sampling, dari 1266 orang mahasiswa calon guru yang telah mengikuti Program Pengenalan Lapangan (PPL), diperoleh sample sebanyak 304 orang yang terdiri dari Jurusan Pendidikan Bahasa Indonesia, Pendidikan Bahasa Inggris, Pendidikan Jasmani, Pendidikan Sejarah, Pendidikan Geografi, Pendidikan Ekonomi, Pendidikan Luar Sekolah, Pendidikan Matematika, dan pendidikan Biologi. Untuk mengetahui gambaran mengenai teaching efficacy dan pedagogical content knowledge digunakan statistic deskriptif, sedangkan untuk mengetahui pengaruh pedagogical content knowledge terhadap teaching efficacy menggunakan regresi linier sederhana. 


\section{HASIL PENELITIAN DAN PEMBAHASAN}

Aplikasi SPSS 25 digunakan untuk mengkategorikan variabel pedagogical content knowledge dan teaching efficacy menjadi tiga kategori yaitu tinggi, sedang dan rendah. Skor tertinggi untuk variabel pedagogical content knowledge (PCK) sebesar 229 dan terendah sebesar 117. Dari data tersebut diperoleh rata-rata (mean) sebesar 185,56, nilai tengah (median) 183 kemudian diperoleh juga standar deviasi sebesar 16,194. Selanjutnya, ditentukan kelas interval untuk variabel tersebut menggunakan rumus $1+3,3$ Log $\mathrm{n}$, dimana $\mathrm{n}$ adalah jumlah subjek penelitian. Jumlah subjek dalam penelitian ini sebanyak 304 orang, maka banyaknya kelas interval yang diperoleh adalah $1+3,3 \log 304=9,19$; Rentang data sebesar $229-117=112$. Setelah diketahui rentang antar data, diperoleh kelas interval masing-masing kelompok yaitu 112/9,19 =12,94, kemudian dibulatkan menjadi 13. Adapun distribusi frekuensi untuk variabel pedagogical content knowledge (PCK) dapat di lihat pada Tabel 1.

Tabel 1. Distribusi Frekuensi Variabel PCK

\begin{tabular}{cccc}
\hline No & Interval & Frekuensi & Frekuensi Relatif (\%) \\
\hline 1 & $117-129$ & 1 & 0,33 \\
2 & $130-142$ & 0 & 0 \\
3 & $143-155$ & 2 & 0,66 \\
4 & $156-168$ & 29 & 9,54 \\
5 & $169-181$ & 100 & 32,89 \\
6 & $182-194$ & 98 & 32,24 \\
7 & $195-207$ & 45 & 14,80 \\
8 & $208-220$ & 18 & 5,92 \\
9 & $221-233$ & 11 & 3,62 \\
10 & $\geq 234$ & 0 & 0 \\
& Jumlah & $\mathbf{3 0 4}$ & $\mathbf{1 0 0}$ \\
\hline
\end{tabular}

Variabel PCK menggunakan alat ukut kuesioner yang terdiri atas 46 butir pertanyaan yang disebar ke 304 responden. Untuk pengolahan skor kuesioner, skor maksimal didapatkan 46 x $5=230$ dan skor minimum $46 \times 1=46$. Dari skor tersebut diperoleh nilai rata-rata (Mean) sebesar 138 serta standar deviasi ideal (SD) sebesar 30,67 dibulatkan menjadi 31. Berdasarkan perhitungan tersebut kategori variabel PCK dapat di lihat pada Tabel 2.

Tabel 2. Distribusi Kecenderungan Variabel PCK

\begin{tabular}{cccccc}
\hline No & Skor & F & $\begin{array}{c}\text { Frekuensi } \\
\text { Relatif }(\%)\end{array}$ & $\begin{array}{c}\text { Frekuensi } \\
\text { Kumulatif }\end{array}$ & Keterangan \\
\hline 1 & $\mathrm{X}>169$ & 272 & 89,47 & 89,47 & Tinggi \\
2 & $169 \leq \mathrm{X} \leq 107$ & 32 & 10,53 & 100 & Sedang \\
3 & $\mathrm{X}<107$ & 0 & 0 & 100 & Rendah \\
& Jumlah & $\mathbf{3 0 4}$ & $\mathbf{1 0 0}$ & & \\
\hline
\end{tabular}

Tabel 2. menunjukkan bahwa dalam kecenderungan variabel PCK bahwa sebagian besar mahasiswa FKIP berada pada kategori tinggi yaitu sebanyak 
272 orang atau sebesar 89,47 persen. Sedangkan sisanya sebanyak 32 orang atau sebesar 10,53 persen berada pada kategori sedang. Artinya, mahasiswa calon guru memiliki kemampuan dalam memahami metode pembelajaran efektif untuk menjelaskan materi tertentu dan juga memiliki pemahaman mengenai bagaimana cara menyampaikan materi pembelajaran agar lebih mudah dipahami oleh siswa. Hal tersebut sejalan dengan pernyataan (Shulman, 2012) yakni pedagogical knowledge berhubungan dengan cara maupun proses pembelajaran yang terdiri dari pengetahuan tentang manajemen kelas dan tugas, merencanakan pembelajaran serta juga proses pembelajaran. Sama halnya dengan hasil penelitian yang menyebutkan bahwa dari 746 sampel calon guru terdapat empat struktur pengetahuan pedagogis yaitu melibatan pengetahuan tentang pengajaran, manajemen kelas, penilaian dan heterogenitas siswa (Depaepe \& König, 2018).

Untuk penskoran pada variabel teaching efficacy, dari hasil pengoahan data kuesioner didapatkan bahwa skor terendah adalah sebesar 96 dan skor tertinggi 150. Data tersebut menunjikkan juga rata-rata (mean) sebesar 120,58, nilai tengah (median) 118 , serta standar deviasi 10,965. Penentuan kelas interval menggunakan rumus $1+3,3$ Log $n$, dimana $n$ yaitu jumlah subjek penelitian yakni sebanyak 304 orang, Kemudian diperoleh banyaknya kelas interval $1+3,3 \log 304=9,19$; dengan rentang data sebesar $150-96=54$. Setelah diketahui rentang data, diperoleh kelas interval masing-masing kelompok yakni $54 / 9,19=5,87$, dibulatkan menjadi 6 . Untuk distribusi frekuensi variable PCK dapat dilihat pada Tabel 3.

Tabel 3. Distribusi Frekuensi Variabel Teaching Efficacy

\begin{tabular}{cccc}
\hline No & Interval & Frekuensi & Frekuensi Relatif (\%) \\
\hline 1 & $96-101$ & 4 & 1,32 \\
2 & $102-107$ & 19 & 6,25 \\
3 & $108-113$ & 53 & 17,43 \\
4 & $114-119$ & 89 & 29,28 \\
5 & $120-125$ & 60 & 19,74 \\
6 & $126-131$ & 31 & 10,20 \\
7 & $132-137$ & 15 & 4,93 \\
8 & $138-143$ & 16 & 5,26 \\
9 & $\geq 144$ & 17 & 5,59 \\
\hline & Jumlah & $\mathbf{3 0 4}$ & $\mathbf{1 0 0}$
\end{tabular}

Variabel teaching efficacy diukur dengan menggunakan kuesioner terdiri dari 30 item pertanyaan yang diadopsi dari Science Teaching Efficacy Instrument diberikan kepada 304 orang mahasiswa FKIP. Penilaian skor maksimal 30x5 = 150 dan skor minimal 30x1 = 30 kemudian diperoleh rata-rata (mean) sebesar 90 dan standar deviasi sebesar 20. Berdasarkan perhitungan tersebut didapatkan tiga kategorisasi yang dapat dilihat pada Tabel 4.

Kecenderungan variabel teaching efficacy calon guru dapat dilihat pada Tabel 4. Sebagian besar mahasiswa FKIP atau sebanyak 86,18 persen berada pada kategori tinggi, sedangkan sisanya yaitu sebesar 13,82 persen berada pada kategori sedang. Artinya mayoritas mahasiswa calon guru di FKIP Universitas Siliwangi memiliki keyakinan dalam pengelolaan kelas dan pelaksanaan 
pembelajaran yang efektif melalui strategi pembelajaran, manajemen kelas, serta bagaimana melibatkan siswa (student engagement). Guru yang efikasi dirinya rendah tidak dapat melakukan berbagai kegiatan yang mereka yakini dengan kemampuannya, kurang gigih menangani siswa bermasalah, kurang usaha dalam mencari materi pembelajaran, serta materi pelajaran tidak diajarkan kembali melalui cara yang dimengerti oleh siswa. Hal tersebut sejalan dengan hasil penelitian Ashton \& Webb (Schunk, 2012) menyebutkan bahwa guru dengan efikasi diri yang tinggi relatif menciptakan suasana positif di dalam lingkungan kelas, memotivasi ide siswa-siswanya, serta memfasilitasi kebutuhan siswanya.

Tabel 4. Distribusi Frekuensi Kecenderungan Variabel Teaching Efficacy

\begin{tabular}{cccccc}
\hline No & Skor & F & $\begin{array}{c}\text { Frekuensi } \\
\text { Relatif (\%) }\end{array}$ & $\begin{array}{c}\text { Frekuensi } \\
\text { Kumulatif }\end{array}$ & Keterangan \\
\hline 1 & $\mathrm{X}>110$ & & 262 & 86,18 & Tinggi \\
2 & $70 \leq \mathrm{X} \leq 110$ & & 42 & 13,82 & Sedang \\
3 & $\mathrm{X}<70$ & 0 & 100 & 100 & Rendah \\
& Jumlah & $\mathbf{3 0 4}$ & $\mathbf{1 0 0}$ & & \\
\hline
\end{tabular}

Pengujian regresi linier sederhana dilakukan dengan menggunakan bantuan aplikasi SPSS 25. Variabel pedagogical content knowledge (PCK) berkorelasi dengan teaching efficacy sebesar 68,8 persen sedangkan variabel teaching efficacy dipengaruhi oleh variabel PCK sebesar 47,3 persen. Persamaan regresi linier sederhana $\hat{Y}=41,489+0,427 X$ menunjukkan bahwa teaching efficacy calon guru dapat diprediksi dengan maupun tanpa adanya pengaruh dari PCK. Peningkatan PCK sebesar satu satuan akan dapat meningkatkan teaching efficacy sebesar 0,427 satuan. Hasil uji hipotesis pada taraf signifikansi 95 persen menunjukkan bahwa PCK memiliki pengaruh signifikan kepada teaching efficacy. Hasil uji hipotesis tersebut sejalan dengan hasil penelitian (Richardson et al., 2017) bahwa teaching efficacy beliefs influence pedagogical content knowledge.

Berdasarkan hasil penelitian teaching efficacy calon guru kecenderungan bahwa mayoritas mahasiswa FKIP Universitas Siliwangi terdapat dalam kategori yang tinggi yakni 86,18 persen. Artinya mahasiswa calon guru sudah memiliki keyakinan akan kemampuan dirinya dalam mengajar. Teaching efficacy merupakan elemen penting dalam pendidikan guru. Teaching efficacy sebagai penentu dalam perilaku mengajar guru tentang kemampuannya dalam melibatkan siswa pada saat proses pembelajaran (Richardson et al., 2017). Inti dari proses pendidikan adalah proses pembelajaran. Guru sebagai pemeran utama dalam proses pembelajaran harus memiliki wawasan dan keterampilan khusus dalam menggabungkan pengetahuan materi, kurikulum, belajar, pembelajaran, juga siswa. Sebagaimana diungkapkan oleh (Richardson et al., 2017) bahwa mengajar merupakan upaya kompleks yang membutuhkan pengetahuan tentang konten, pedagogi, konten pedagogies, pemahaman tentang peserta didik, evaluasi dan kurikulum.

Untuk menjadi seorang guru professional harus memiliki pemahaman mengenai materi yang ajar (content knowledge) serta wawasan mengenai cara mendidik (pedagogical knowledge) yang tergabung dalam Pedagogical content 
knowledge (PCK). Hal tersebut dipertegas dengan pernyataan highly developed $P C K$ would produce superior instructional experiences for students. PCK is now viewed as the central element of teacher development (Smit, Weitzel, Blank, Rietz, \& Tardent, 2017).

\section{SIMPULAN}

Berdasarkan hasil penelitian dapat ditarik kesimpulan bahwa variabel pedagogical content knowledge (PCK) dan teaching efficacy mahasiswa calon guru berada pada kategori tinggi. Kemudian, secara simultan pedagogical content knowledge (PCK) berpengaruh kepada teaching efficacy calon guru.

Dari hasil penelitian penulis menyarankan bagi mahasiswa yang merupakan calon guru, agar memiliki kemampuan pedagogical content knowledge yang dapat mengingkatkan teaching efficacy. Dengan meningkatnya teaching efficacy, mahasiswa yang merupakan calon guru dapat memfasilitasi siswa jauh lebih baik lagi dalam menguasai materi pembelajaran di kelas, serta mengatasi permasalahan pembelajaran yang dialami siswa.

\section{DAFTAR RUJUKAN}

Creswell, J. (2011). Research Design: Pendekatan Metode Kualitatif, Kuantitatif, dan Campuran. Yogyakarta: Pustaka Pelajar.

d'Alessio, M. A. (2018). The Effect of Microteaching on Science Teaching Self-Efficacy Beliefs in Preservice Elementary Teachers. Journal of Science Teacher Education, 29(6), 441-467. https://doi.org/10.1080/ 1046560X.2018.1456883

Depaepe, F., \& König, J. (2018). General pedagogical knowledge, self-efficacy and instructional practice: Disentangling their relationship in pre-service teacher education. Teaching and Teacher Education, 69, 177-190. https://doi.org/10.1016/j.tate.2017.10.003

Eggen, P., \& Kauchak, D. (2012). Strategi dan Model Pembelajaran Mengajarkan Konten dan Keterampilan Berpikir Edisi Keenam. Jakarta: PT. Indeks Permata Puri Media.

Hoy, A. W., \& Spero, R. B. (2005). Changes in teacher efficacy during the early years of teaching: A comparison of four measures. Teaching and Teacher Education, 21(4), 343-356. https://doi.org/10.1016/ j.tate.2005.01.007

Redmon, R. (2007). Impact of Teacher Preparation upon Teacher Efficacy. Online Submission, 1-20.

Richardson, G. M., Byrne, L. L., \& Liang, L. L. (2017). Making learning visible : Developing preservice teachers ' pedagogical content knowledge and teaching efficacy beliefs in environmental education. Applied 
Environmental Education \& Communication, 0(0), 1-16. https://doi.org/ 10.1080/1533015X.2017.1348274

Schunk, D. H. (2012). Learning Theories An Educational Persfective. Yogyakarta: Pustaka Pelajar.

Shulman, L. E. E. S. (2012). Understand : Knowledge, 15(2), 4-14.

Smit, R., Weitzel, H., Blank, R., Rietz, F., \& Tardent, J. (2017). Interplay of secondary pre-service teacher content knowledge ( $\mathrm{CK}$ ), pedagogical content knowledge ( PCK ) and attitudes regarding scientific inquiry teaching within teacher training. Research in Science \& Technological Education, 5143(July), 1-23. https://doi.org/10.1080/02635143.2017. 1353962 